
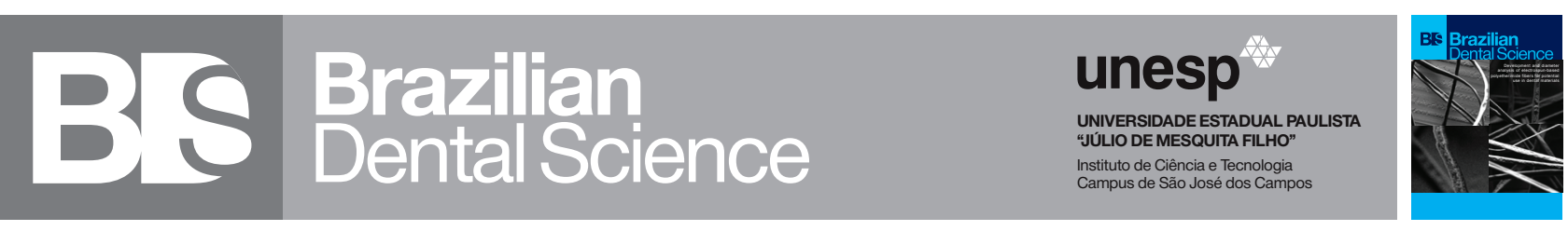

\title{
Standardized Approach in Leakage Studies: Sealing Ability of Endodontic Sealers
}

Galvin Sim Siang LIN ${ }^{1,2}$, Nik Rozainah Nik Abdul GHANI ${ }^{2}$, Tahir Yusuf NOORANI ${ }^{2}$

1 - Klinik Pergigian Bau, Ministry of Health Malaysia, 94000, Bau, Sarawak, Malaysia.

2 - Conservative Dentistry Unit, School of Dental Sciences, Universiti Sains Malaysia, Health Campus, 16150, Kubang Kerian, Kota Bharu, Kelantan, Malaysia.

\section{INTRODUCTION}

$\mathrm{D}$ ear Editor, we read with great interest the article by Galledar S et al. [1], recently published in your esteemed journal which addressed the apical microleakage of three different root canal sealers, namely MTA Fillapex, AH 26 and Endofill Sealer. Firstly, we would like to congratulate the authors for conducting this study which has a profound impact especially to the scientific community and clinical endodontic practice. Undeniably, sealing ability tests are still being carried out in endodontics research due to the established concept that inadequate obturation can cause bacterial reinfection $[2,3]$. There are a substantial number of studies that have been performed to evaluate the sealing ability of different types of endodontic sealers using several techniques such as dye leakage, bacterial culture, glucose penetration, and fluid filtration methods [3]. However, there is still an elusive conclusion regarding the appropriateness of such methodologies owing to the lack of standardization.

The first point that we would like to highlight is the use of methylene blue dye. We do agree to a certain extent that methylene blue dye was once considered a most commonly used tracer for dye penetration testing [3]. Nevertheless, when conducting dye leakage study, attention should be given to the interference of fluid movement by air entrapment in the root canal. Some studies suggested that dye leakage studies should be carried out under low-pressure environment or in a vacuum. With this modification, a significant amount of dye leakage as compared to conventional dye leakage method was reported [4, 5]. Another factor that needs to be considered during dye leakage testing is the direction of tooth sectioning. Longitudinal sectioning of the teeth enables better visualization of the dye material along the dentine-sealer interface. However, dye dissolution and a lower probability of cutting through the deepest part of the dye leakage due to random cutting axis selection may underestimate the results $[6,7]$. A previous study proposed the use of transverse sectioning technique to evaluate the sealing ability, as it offers multiple cross-sectional areas throughout the canal [8]. Additionally, longitudinal sectioning technique may result in the loss of dentinal tissues and it only allows the researcher to identify the presence of dye in the sectioned area [3].

The second point we would like to address is the standardization of the methodology. Laboratory-based leakage studies should develop well-controlled conditions that are reliable enough to produce comparable results, but the reported study demonstrated a lack of proper design with the absence of well-controlled groups that gave rise to several confounding factors which reduced the reliability of the test. Leakage studies using nonpaired teeth were found to have extremely wide anatomical 
variability of the root canal [9]. Thus, the effect of canal anatomy on the sealing ability would be determined rather than the endodontic sealer itself. Therefore, we propose that leakage studies should use matched-pair contralateral teeth from the same individual and undergo strict radiographic screening procedures of the root canal anatomy such as radiographic examination of buccolingual and mesiodistal aspect of the root canal with high-resolution $\mathrm{X}$-ray tomography scans to minimize internal bias and provide a consistent baseline that would enhance the validity of the study [10].

Hence, the critics of laboratory leakage studies should be considered, and new guidelines should be established to allow future studies to be of better quality. Simple comparison of leakage studies must be thoroughly re-evaluated to warrant their clinical significance. Obtaining contralateral teeth is of course challenging and will result in a smaller sample size, but it will provide well-balanced groups and the results will enable a better understanding of the sealing ability. Finally, we would like to thank the authors for the insightful discussion point in the published article, and we hope to read more studies with better and well-controlled methodological approach to evaluate the sealing ability of endodontic sealers.

\section{REFERENCES}

1. Galledar S, Farhang R, Abazari M, Negahdar P. Evaluation of the apical microleakage of MTA Fillapex, AH26, and Endofill sealers. Braz Dent Sci. 2020;23(3). doi:10.14295/bds.2020.v23i3.1895.

2. Viapiana R, Moinzadeh AT, Camilleri L, Wesselink PR, Tanomaru Filho M, Camilleri J. Porosity and sealing ability of root fillings with gutta-percha and BioRoot RCS or AH Plus sealers. Evaluation by three ex vivo methods. Int Endod J. 2016;49(8):774-82. doi:10.1111/iej.12513.

3. Jafari F, Jafari S. Importance and methodologies of endodontic microleakage studies: A systematic review. J Clin Exp Dent. 2017;9(6):e812-e9. doi:10.4317/jced.53604.

4. Wu MK, De Gee AJ, Wesselink PR. Fluid transport and dye penetration along root canal fillings. Int endod J. 1994;27(5):233-8.

5. Wimonchit S, Timpawat S, Vongsavan N. A comparison of techniques for assessment of coronal dye leakage. J Endod. 2002;28(1):1-4. doi:101097/00004770-200201000-00001.

6. Camps J, Pashley D. Reliability of the dye penetration studies. J Endod. 2003;29(9):592-4. doi:10:1097/00004770-200309000-00012.

7. Ahlberg KM, Assavanop P, Tay WM. A comparison of the apical dye penetration patterns shown by methylene blue and india ink in root-filled teeth. Int Endod J. 1995;28(1):30-4.

8. Sadighpour L, Rezaei S, Geramipanah F, Mohammadi M, Choubchian S Comparison of two techniques for evaluation of coronal leakage along of a glass fiber post. J Dent (Tehran). 2010;7(3):124-31.

9. HinES, Wu MK, Wesselink PR, Shemesh H. Effects of self-adjusting file, Mtwo, and ProTaper on the root canal wall. JEndod. 2013;39(2):262-4. doi:10.1016/j.joen.2012.10.020.

10. LiN GSS, NiK Abdul Ghani NR, Noorani TY,KamarudiN A. Apical sealing ability of different endodontic sealers using glucose penetration test: a standardized methodological approach. Cumhuriyet Dent J. 2020;23(2):7987. doi:10.7126/cumudj.704107.

\section{Nik Rozainah Nik Abdul Ghani}

\section{(Corresponding address)}

Conservative Dentistry Unit, School of Dental Sciences, Universiti Sains Malaysia,

Health Campus, 16150, Kubang Kerian, Kota Bharu, Kelantan, Malaysia.

Date submitted: 2020 Aug 22

Email: rozainah@usm.my 